\title{
RESUMEN
}

\section{“La doctrina de la justificación por la fe - Parte I: ¿En las}

huellas de los reformadores?" - El presente estudio es el primero de una serie de tres artículos donde se estudia el asunto de la justificación por la fe con énfasis en la perspectiva veterotestamentaria. En esta primera parte se revisa de manera panorámica el debate sobre la justificación en el contexto de las distintas perspectivas teológicas cristianas desde tiempos de la Reforma hasta la actualidad. A partir de la segunda parte, en el siguiente artículo, el estudio se focaliza en la perspectiva veterotestamentaria. Por último, el estudio concluye estableciendo una serie de implicancias que tiene la discusión de este tema en el Antiguo Testamento para la comprensión de la doctrina de la justificación.

Palabras clave: Antiguo Testamento, justificación por la fe, justicia de Dios, justicia de Cristo, Reforma Protestante, Nueva perspectiva de Pablo

\section{ABSTRACT}

"The Doctrine of Justification by Faith - Part I: In the Footsteps of the Reformers?" - This is the first part of a series of three articles where the author examines the issue of justification by faith with emphasis on the Old Testament perspective. In this first part, the debate on justification in the context of the different Christian theological perspectives from the time of the Reformation to the present is reviewed in a panoramic way. In the second part, in the following article, the study focuses on the Old Testament perspective. Finally, the study concludes establishing a series of implications that the discussion of this topic in the Old Testament has for the understanding of the doctrine of justification.

Keywords: Old Testament, Justification by Faith, Righteousness of God, Righteousness of Christ, Protestant Reformation, New Perspective on Paul 


\title{
LA DOCTRINA DE LA JUSTIFICACIÓN POR LA FE - PARTE I: ¿EN LAS HUELLAS DE LOS REFORMADORES?
}

\author{
Richard M. Davidson
}

\section{Introducción}

En el que probablemente sea el libro más antiguo de la Biblia, el patriarca Job hizo una aguda pregunta: “¿Cómo puede el hombre justificarse ante Dios?” (Job 2:9). A lo largo de los siglos, la cuestión respecto a la posición de uno ante Dios, es decir, cómo uno es justificado por Él, ha sido vista como la más crucial que enfrentan los seres humanos, y es fundamental para muchas otras preguntas que pueden derivarse de ella.

Martín Lutero afirmó que "si perdemos la doctrina de la justificación, perdemos simplemente todo". ${ }^{1}$ Lutero creía que la justificación solo por la fe "es el artículo con y por el cual la iglesia permanece, sin el cual se cae". ${ }^{2}$ En

*Este documento fue presentado en la Reunión Anual de la Adventist Theological Society, “The Heritage of the Reformation”, Boston MA, 18 de noviembre de 2017. Agradezco a Joel Iparraguirre por las sugerencias dadas para poder dividir este documento en tres partes y también por traducirlo al "hermoso idioma celestial", el español.

${ }^{1}$ Martin Luther, Lectures on Galatians, 1535, Chapters 1-4, vol. 26, Luther's Works, ed. Jaroslav Pelikan y Walter A. Hansen, trad. Jaroslav Pelikan (Saint Louis, MO: Concordia, 1963), 26.

${ }^{2}$ Martin Luther, What Luther Says: An Anthology, ed. Ewald M. Plass, 3 vols. (St. Louis: Concordia, 1959), 2:704n5. Aunque estas palabras no fueron acuñadas por el propio Lutero, es ampliamente reconocido que representan bien su pensamiento. Véase Paul Rhodes 
el prefacio a sus 45 tesis escritas en 1537, Lutero hace esta apasionada súplica:

El artículo de la justificación es el gran maestro y príncipe, el señor, el gobernante y el juez sobre todo tipo de doctrinas; preserva y gobierna toda la doctrina de la Iglesia y eleva nuestra conciencia ante Dios. Sin este artículo el mundo está en absoluta muerte y oscuridad. ${ }^{3}$

Juan Calvino, a su vez, consideró que la doctrina de la justificación era "la principal bisagra sobre la cual gira la religión”. Además, explicó: "A menos que primero comprenda cuál es su posición ante Dios y cuál es el juicio que ejerce sobre usted, no tiene fundamento en el que pueda establecerse su salvación, o sobre el cual se pueda elevar la piedad hacia Dios". ${ }^{4}$

Elena G. de White, tras la sesión de la Asociación General de 1888, escribió que "la luz que he recibido de Dios coloca este importante tema [justificación por la fe] más allá de todo interrogante en mi mente". ${ }^{5} \mathrm{Al}$ mismo tiempo, advirtió que este tema puede producir confusión y es el objeto de los ataques de Satanás:

Una y otra vez me ha sido presentado el peligro de abrigar, como pueblo, ideas falsas sobre la justificación por la fe. Por

Eddy, James K. Beilby y Steven E. Enderlein, “Justification in Historical Perspective”, en Justification: Five Views, ed. James K. Beilby y Paul Rhodes Eddy (Downers Grove, IL: IVP Academic, 2011), 24.

${ }^{3}$ Luther, What Luther Says, 2:703.

${ }^{4}$ John Calvin, Institutes of the Christian Religion (ed. 1559), 3.11.1 (trad. Beveridge).

${ }^{5}$ Elena G. de White, Fe y obras (Buenos Aires: Asociación Casa Editora Sudamericana, 1984), 18. 
años se me ha mostrado que Satanás trabajaría de una manera especial para confundir las mentes en este punto. ${ }^{6}$

Lutero había dado advertencias similares:

Quien cae de la doctrina de la justificación es ignorante con respecto a Dios y es un idólatra. ... Porque una vez que esta doctrina sea socavada, no queda nada más que puro error, hipocresía, maldad e idolatría, sin importar cuán grande santidad se manifieste en él externamente. ${ }^{7}$

Ningún error es tan insignificante, tan torpe, tan desgastado como para no agradar supremamente a la razón humana y para seducirnos si estamos sin el conocimiento y la contemplación de este artículo [de la justificación]. ${ }^{8}$

En este contexto, es necesario entender claramente la verdad acerca de la justificación por la fe en vista de su importancia en la vida del creyente. Tradicionalmente, este tema ha sido discutido mayormente desde la perspectiva paulina, recibiendo poca atención desde la óptica del AT. Por lo tanto, el presente estudio es el primero de una serie de tres artículos donde se estudia el asunto de la justificación por la fe desde la perspectiva veterotestamentaria. En esta primera parte, sin embargo, se revisa de manera panorámica el debate sobre la justificación en el contexto de las distintas vertientes teológicas cristianas desde tiempos de la Reforma hasta la actualidad.

${ }^{6}$ Ibíd., 15.

${ }^{7}$ Luther, Lectures on Galatians, 1535, Chapters 1-4, 395-6.

${ }^{8}$ Luther, What Luther Says, 2:703. 


\section{El debate sobre la justificación: Diferentes puntos de vista}

\section{La visión protestante tradicional9}

La Reforma Protestante ocurrió principalmente en protesta contra el entendimiento católico de la justificación, al ser considerado por los teólogos protestantes como una grave distorsión de la verdad bíblica.

Basándose en los escritos de Pablo, especialmente de Romanos y Gálatas, y enraizándose en el AT, Martín Lutero entendió la justificación como "la justicia ajena de Cristo". ${ }^{10}$

${ }^{9}$ Esta representa la comprensión de los reformadores magisteriales, en particular, de Martín Lutero, Juan Calvino y Felipe Melanchthon, cuyos puntos de vista sobre la justificación fueron seguidos en su mayor parte por Arminio (arminianismo) y Juan Wesley (metodismo), y muchos otros teólogos y tradiciones protestantes. Para un tratamiento reciente de la doctrina tradicional de la Reforma, véase, especialmente, Thomas Schreiner, Faith Alone: The Doctrine of Justification: What the Reformers Taught. . . and Why It Still Matters (Grand Rapids, MI: Zondervan, 2015). Para una discusión (con bibliografía) de la historia de otros puntos de vista sobre la justificación, tales como el de la iglesia de los primeros siglos (p. ej., Orígenes, Agustín) la Edad Media latina (p. ej., Anselmo y Tomás de Aquino), los anabaptistas y la "Reforma Radical" (p. ej., Menno Simons), el protestantismo liberal (p. ej., Albrecht Ritschl), reinterpretaciones existenciales (Paul Tillich y Rudolf Bultmann), Karl Barth, la teología de la Liberación y la teología feminista (p. ej., Elsa Tamez), las teologías pentecostales (Frank Macchia) y la teología luterana finlandesa (Tuomo Mannermaa, Veli-Matti Kärkkkäinen), véase Eddy, Beilby y Enderlein, "Justification in Historical Perspective", 13-52.

${ }^{10} \mathrm{La}$ escuela finlandesa de interpretación luterana, en diálogo con la teología ortodoxa rusa, afirma que la visión de Lutero estaba más cerca del entendimiento ortodoxo de la teosis o "deificación", y que para Lutero la justificación no era solo una justicia ajena o externa: "En línea con la teología católica, justificación significa tanto declarar justo como hacer 
Esto se oponía a la comprensión agustiniana en la que la justificación, aunque completada por la gracia de Dios, era algo adherido al receptor humano.

Lutero afirmó que el cristiano justificado era simul justus et peccator. R. C. Sproul explica:

El famoso dicho de Lutero, simul justus et peccator va al corazón de la cuestión sobre la justificación forense. La frase latina significa "al mismo tiempo justo y pecador". Esta condición simultánea se refiere a la situación en la que el pecador es contado como justo de manera forense en virtud de la imputación de Cristo, mientras que permanece todavía pecador en y por sí mismo.

Lutero no quiso decir que el pecador, quien es todavía pecador, es una persona sin cambios. El pecador que tiene fe salvadora es una persona regenerada. El Espíritu Santo habita en él. No obstante, sigue siendo injusto en sí mismo. Tampoco significa que el pecador no está en un proceso real de santificación por el cual se está volviendo justo. Aquellos que poseen fe salvadora, necesaria, inevitable e inmediatamente comienzan a manifestar los frutos de la fe, que son obras de obediencia. Sin embargo, la base de la justificación de la persona sigue siendo sola y exclusivamente la justicia imputada de Cristo. Es por su justicia y solo por su justicia que el pecador es declarado justo. ${ }^{11}$

justo”. Veli-Matti Kärkkäinen, “Deification View”, en Justification: Five Views, ed. James K. Beilby y Paul Rhodes Eddy (Downers Grove, IL: IVP Academic, 2011), 222. Para una crítica a este punto de vista, desde la perspectiva de la interpretación tradicional de Lutero, véase Michael S. Horton, "Traditional Reformed View", en Justification: Five Views, 83ss, donde el autor responde a Kärkkäinen, "Deification View", 244-9. Véase especialmente Horton, "Traditional Reformed View", 122ss.

${ }^{11 R}$. C. Sproul, "The Forensic Nature of Justification", en Justification by Faith Alone: Affirming the Doctrine by Which the Church 
Para Lutero, la justificación no se efectuaba ante los ojos de los hombres, sino coram Deo, "ante el rostro de Dios" o, como lo expresara Felipe Melanchthon, "ante el tribunal divino celestial". La gracia no era una sustancia sagrada que bajaba de Dios y era insertada en ser humano; al contrario, era una actitud de favor divino.

Melanchthon continuó trabajando los conceptos de Lutero al utilizar un lenguaje de imputación más preciso. La justificación fue presentada como el acto divino de declarar justos a los pecadores, basándose en la justicia extrínseca e imputada de Cristo. Esto estaba en contraste con Agustín, quien vio la justificación como la acción de Dios de hacer justo al pecador por medio de la conversión de su voluntad. ${ }^{12}$

La doctrina de la justificación en Calvino está profundamente en deuda con los conceptos desarrollados por Lutero y Melanchthon. ${ }^{13}$ Calvino enfatizó elocuentemente la naturaleza forense de la justificación por la justicia imputada de Cristo, al resumir claramente la doctrina en sus Institución:

Un hombre será justificado por la fe cuando, excluido de la

and the Individual Stands or Falls, ed. John Kistler, ed. rev. y act. (Morgan, PA: Soli Deo Gloria, 2003), 33-4. Cursiva en el original.

${ }^{12} \mathrm{El}$ Melanchthon maduro logró captar el concepto del libre albedrío humano en el que la salvación estaba verdaderamente disponible para todos los seres humanos, a diferencia de Calvino y Lutero que se aferraron a la doctrina de la predestinación. Véase Gregory B. Graybill, Evangelical Free Will: Philip Melanchthon's Journey on the Origins of Faith (New York: Oxford University Press, 2010).

${ }^{13}$ Para un resumen de los puntos de vista de Calvino sobre la justificación y su deuda con Lutero y Melanchthon, véase especialmente, Karla Wübbenhorst, "Calvin's Doctrine of Justification: Variations on a Lutheran Theme", en Justification in Perspective: Historical Developments and Contemporary Challenges, ed. Bruce L. McCormack (Grand Rapids, MI: Baker, 2006), 99-118. 
justicia de las obras, se aferre por la fe a la justicia de Cristo y, vestido de ella, aparezca ante los ojos de Dios no como pecador sino como justo. En consecuencia, simplemente interpretamos la justificación como la aceptación por la cual Dios nos recibe en Su favor como si fuéramos justos. Y decimos que esta justificación consiste en el perdón de los pecados y la imputación de la justicia de Cristo. ${ }^{14}$

Justificar, por lo tanto, no es otra cosa que absolver del cargo de culpabilidad, como si la inocencia estuviese probada. De este modo, cuando Dios justifica por la intercesión de Cristo, no nos absuelve sobre la base de una prueba de nuestra propia inocencia, sino por una imputación de justicia, de modo tal que aunque no seamos justos por nosotros mismos, seamos considerados justos en Cristo. ${ }^{15}$

La justicia de Cristo... debe comparecer ante el tribunal en nuestro nombre y avalarnos en el juicio. Recibida de Dios, esta justicia es traída a nosotros y nos es imputada como si fuera nuestra. ${ }^{16}$

Para Calvino, la justificación no se encuentra separada de la unión con Cristo. De hecho,

Calvino habla de una unión mística con Cristo forjada por el Espíritu Santo, Autor de la fe, Creador de esta comunidad de justicia, y de esta unión surge una doble gracia: justificación y santificación. Son simultáneas, y aunque pueden ser distinguidas, no se pueden separar. ${ }^{17}$

${ }^{14}$ Calvin, Institutes (ed. 1559), 3.11.2.

${ }^{15}$ Ibíd., 3.11.3. Cursiva en el original.

${ }^{16}$ John Calvin, Institutes of the Christian Religion (ed. 1536), 1.32 (trad. Battles).

${ }^{17}$ Wübbenhorst, “Calvin's Doctrine of Justification”, 115. 


\section{Asimismo, él reconoce}

que estamos desprovistos de este don incomparable [de la justificación] hasta que Cristo llegue a ser nuestro. Por lo tanto, a esa unión entre la cabeza y sus miembros, a la residencia de Cristo en nuestros corazones, en fin, a la unión mística, le asignamos el rango más elevado; Cristo cuando llega a ser nuestro, nos hace participantes con él en los dones con los que fue dotado. ${ }^{18}$

De este modo, aunque Calvino comprendió que la justificación y la santificación ocurren simultáneamente y son inseparables, también creía que debían distinguirse.

Como Cristo no se puede dividir en partes, las dos cosas, justificación y santificación, que percibimos unidas en él, son inseparables. Por lo tanto, a quien Dios ha recibido en su favor, lo presenta con el Espíritu de adopción, cuya acción los forma nuevamente a Su imagen. Y si el brillo del sol no puede ser separado de su calor, ¿debemos, pues, decir que la tierra se calienta por la luz y se ilumina por el calor? Nada puede ser más apropiado al asunto en cuestión que este símil. El sol, por su calor, vivifica y fecunda la tierra; por sus rayos la irradia y la ilumina. Aquí hay una conexión mutua e indivisible, y sin embargo, la razón misma nos prohíbe transferir las propiedades peculiares de la una a la otra. ${ }^{19}$

${ }^{18}$ Calvin, Institutes (ed. 1559), 3.11.10.

${ }^{19}$ Ibíd., 3.11.6. El Calvino maduro desea tanto subrayar este punto que en su última edición de la Institución de 1559, invierte el orden de su tratamiento de la justificación y la santificación, poniendo a esta última primero. 
En tanto que los reformadores magisteriales (especialmente Lutero, Calvino y Melanchthon) enfatizaron diferentes aspectos de la doctrina y experimentaron su propio crecimiento personal en la comprensión de su significado, ${ }^{20}$ hacia 1540 había un consenso general en cuanto a sus características esenciales. Alister McGrath resume los puntos principales de este consenso:

1. La justificación es la declaración forense de que el cristiano es justo, en vez del proceso por el cual él o ella es hecho justo. Implica un cambio de estatus más que de naturaleza.

2. Se hace una distinción deliberada y sistemática entre justificación (el acto externo por el cual Dios declara justo al creyente) y santificación o regeneración (el proceso interno de renovación por el Espíritu Santo).

3. La justificación como la justicia ajena de Cristo, [es] imputada al creyente y externa a él, no una justicia que le es inherente, localizada en él, o que en alguna forma le pertenece. La justificación tiene lugar per $f$ dem propter Christum ["a través de la fe por cuenta de Cristo"], entendiéndose la fe como el medio de justificación dado por Dios y los méritos de Cristo como el fundamento de la justificación dada por Dios. ${ }^{21}$

Este entendimiento básico de la justificación fue aceptado por los reformadores posteriores tales como Jacobo

${ }^{20}$ Para más detalles y fundamentación, véase, por ejemplo, Bruce L. McCormack, ed., Justification in Perspective: Historical Developments and Contemporary Challenges (Grand Rapids, MI: Baker, 2006); Schreiner, Faith Alone, 37-63. Cursiva en el original.

${ }^{21}$ Alister McGrath, Justification by Faith (Grand Rapids, MI: Zondervan, 1988), 61. Cursiva en el original. 
Arminio ${ }^{22}$ y Juan Wesley, ${ }^{23}$ y se incorporó a los principales credos protestantes al tratar el tema de la justificación. ${ }^{24}$

\section{La visión protestante vs. la visión católica}

Los reformadores magisteriales antes mencionados (y podríamos agregar también a Arminio y Wesley) rechazaron la visión católica romana sobre la justificación. R. C. Sproul resume las cuestiones básicas en juego en el rechazo de la Reforma a la comprensión católica respecto a la jus-

${ }^{22}$ Véase la propia declaración de Arminio: "Es la justificación por la cual un hombre, que es pecador, pero a la vez un creyente, siendo colocado ante el trono de la gracia que se erige en Cristo Jesús la Propiciación, es contado y pronunciado por Dios, el justo y misericordioso juez, justo y digno de recompensa de justicia, no en sí mismo sino en Cristo, por gracia, de acuerdo al evangelio, a la alabanza de la justicia y gracia de Dios y a la salvación de la persona justificada misma' (Rom. iii. 24-26; 3, 4, 5, 10, 11.)". James Arminius, The Works of James Arminius vol. 1, trad. James Nichols (Auburn, NY: Derby, Miller and Orton, 1853), 598-9. "Yo mismo no soy consciente de haber enseñado o albergado otros sentimientos concerniente a la justificación del hombre ante Dios, que el de aquellos que son sostenidos unánimemente por los reformados y las iglesias protestantes, en lo cual están en completo acuerdo con sus opiniones expresadas". Ibíd., 262. Arminio, sin embargo, como lo hiciera el Melanchthon maduro, extendió la justificación para incluir a quien escogiera aceptarla (y no solo para los electos como es el caso con Lutero y Calvino).

${ }^{23}$ Para un resumen de las opiniones de Jonathan Edwards y Juan Wesley sobre la justificación, véase, por ejemplo, Schreiner, Faith Alone, 80-94.

${ }^{24}$ Véase la Confesión de Fe de Westminster (1647), 11.1-2, citada en Joel Beeke, "Justification by Faith Alone (The Relation of Faith to Justification)", en Justification by Faith Alone, 85. Para este y otros credos protestantes importantes, véase John H. Leith, ed., Creeds of the Churches: A Reader in Christian Doctrine from the Bible to the Present (Garden City, NY: Doubleday, 1963). 
tificación: "En términos sencillos, el asunto se reduce a lo siguiente: ¿Somos justificados por un proceso mediante el cual nos convertimos realmente en justos, o somos justificados por un acto declarativo por el cual somos contados o considerados justos por Dios? ¿Somos declarados justos o somos hechos justos en la justificación?”25

\section{Además, Sproul continúa explicando que}

inseparablemente conectado a la doctrina de la justificación forense está el concepto de imputación. El asunto de la Reforma se enfocó en la distinción entre la justicia infusa y la justicia imputada. Para el catolicismo romano, la justificación ocurre a través de la infusión de la gracia de Cristo, que hace posible la justicia si el creyente acepta y coopera con esta gracia. ${ }^{26}$

Sproul aclara que "los reformadores no excluyeron la infusión de gracia. La gracia es derramada en el alma. El asunto era la base de nuestra justificación. Para los reformadores, la única base era la justicia imputada de Cristo, no la justicia inherente del creyente o la justicia infusa de Cristo". ${ }^{27}$

${ }^{25}$ Sproul, "The Forensic Nature of Justification", 25. Cursiva en el original. "El conflicto sobre la justificación solo por la fe se reduce a esto: ¿es el fundamento de nuestra justificación la justicia de Cristo que se nos imputa a nosotros [el punto de vista de la Reforma], o la justicia de Cristo que está obrando en nosotros [el punto de vista católico]? Para los reformadores, la doctrina de la justificación solo por la fe significaba justificación solo por Cristo y su justicia”. R. C. Sproul, Faith Alone: The Evangelical Doctrine of Justification (Grand Rapids, MI: Baker, 1995), 73.

${ }^{26}$ Sproul, “The Forensic Nature of Justification”, 34.

27Ibíd., 36-7. 
En el Concilio de Trento (1545-1563), la Iglesia Católica Romana, en su Decreto sobre la justificación (1547), no solo rechazó sistemáticamente los principios distintivos de la justificación solo por la fe como fueron adoptados por los reformadores, sino que también anatemizó a cualquiera que creyera o enseñara tales creencias. ${ }^{28}$ Thomas Schreiner re-

${ }^{28} \mathrm{He}$ aquí algunos ejemplos de declaraciones del Concilio de Trento sobre el Decreto de la justificación. Respecto a la justificación solo por la fe: "Si alguno dijere, que el pecador se justifica con la sola fe, entendiendo que no se requiere otra cosa alguna que coopere para conseguir la gracia de la justificación; y que de ningún modo es necesario que se prepare y disponga con el movimiento de su voluntad; sea anatema”. Sesión 6, canon 9, en H. J. Schroeder, Canons and Decrees of the Council of Trent (London: Herder, 1941), 43. El canon 10 rechaza la naturaleza forense de la justificación: "Si alguno dijere, que los hombres son justos sin aquella justicia de Jesucristo, por la que nos mereció ser justificados, o que son formalmente justos por aquella misma, sea anatema”. Ibíd. El Canon 11 insiste en que la justificación tiene lugar a través de la justicia infusa de Cristo, no a través de su justicia imputada: "Si alguno dijere que los hombres se justifican o con la sola imputación de la justicia de Jesucristo, o con solo el perdón de los pecados, excluida la gracia y caridad que se difunde en sus corazones, y queda inherente en ellos por el Espíritu Santo; o también que la gracia que nos justifica, no es otra cosa que el favor de Dios, sea anatema". Citado en John M. MacArthur, "Long before Luther (Jesus and the Doctrine of Justification)", en Justification by Faith Alone, 12. En el capítulo 7 de la sexta sesión del concilio de Trento, la justificación se combina con la santificación: "A esta disposición o preparación se sigue la justificación en sí misma: que no sólo es el perdón de los pecados, sino también la santificación y renovación del hombre interior por la admisión voluntaria de la gracia y dones que la siguen; de donde resulta que el hombre de injusto pasa a ser justo". Schroeder, Canons, 33. En el capítulo 3, la justificación es vista como no solo declarando justo a un hombre sino también como haciéndolo justo: "Si no renaciesen en Jesucristo, jamás serían justificados; pues en esta regeneración se les confiere por el mérito de la pasión de Cris- 
sume las conclusiones más importantes a las que se arribó en Trento en relación a la justificación:

En Trento, la justificación se entendió como un proceso y se definió en términos de justicia inherente. La justificación solo por la fe es categóricamente rechazada, y la justificación se basa, en parte, en obras humanas. Es por eso que también se repudia la noción de que la justicia nos es imputada, junto con la noción de que ninguno puede tener seguridad de la salvación final. ${ }^{29}$

John Gerstner destaca la gran diferencia entre el pensamiento católico y protestante respecto a la justificación desde la perspectiva de la relación entre la fe y las obras. Él señala que, para los protestantes, la justificación es solo por la fe, pero nunca es una fe sin obras. En sus propios términos, "la justificación es solo por fe, pero NO por una fe que está sola'. La justificación es por una fe que OBRA". ${ }^{30}$ Gerstner añade que la justificación es en realidad por las obras, pero no por obras humanas sino por las de Cristo. El pecador recibe las obras de Cristo como si fueran propias. Cristo justifica a su pueblo a través de sus propias obras como si fueran las de los miembros de su pueblo. Ellos hacen estas obras "en

to, la gracia con que son hechos justos". Schroeder, Canons, 30-31. Finalmente, en el capítulo 9 del Decreto sobre la justificación se niega la seguridad de la salvación: "Nadie puede saber con la certidumbre de su fe, la cual no puede sujetarse a error, que ha conseguido la gracia de Dios”. Schroeder, Canons, 35.

${ }^{29}$ Schreiner, Faith Alone, 66.

${ }^{30}$ John H. Gerstner, "The Nature of Justifying Faith," en Justification by Faith Alone, 114. 
su Substituto". "31 "La justificación viene por la fe, a la cual se añaden inmediata e inseparablemente las obras". ${ }^{22}$

Gerstner usa tres fórmulas para ilustrar las opiniones de (1) los protestantes, (2) los católicos y (3) la caricaturización católica común del protestantismo: ${ }^{33}$

1. Punto de vista de la Reforma:

$\mathrm{Fe} \rightarrow$ Justificación + Obras

2. Error católico:

$\mathrm{Fe}+$ Obras $\rightarrow$ Justificación

3. Caricatura romana común del protestantismo:

$\mathrm{Fe} \rightarrow$ Justificación - Obras

En resumen, "la justificación solo por la fe, pero no por una fe que esté sola, es la enseñanza de la Reforma”. ${ }^{34}$

\section{Recientes acercamientos protestantes hacia los católicos}

En los últimos años ha habido una tendencia por parte de un número de evangélicos - al menos en los Estados Unidos de Norteamérica- de participar en un diálogo con los católicos romanos. En un sorprendente giro de los acontecimientos, muchos evangélicos están retornando a Roma, alcanzando un consenso con eruditos católicos romanos, y proclamando que la Reforma fue un malentendido que nunca debió haber ocurrido. Algunos eruditos evangélicos, de

${ }^{31}$ Ibíd., 118.

${ }^{32}$ John H. Gerstner, "Rome NOT Home", en Justification by Faith Alone, 150. Cursiva en el original.

33Ibíd., 150-1.

34Ibíd., 151. 
hecho, han regresado al catolicismo romano.

Scott Hahn, por ejemplo, es un ex-presbiteriano que se ha convertido al catolicismo, y relata su experiencia de regreso en su libro Rome Sweet Home. ${ }^{35}$ Él ahora enseña en el Departamento de Teología en la Universidad Franciscana en Steubenville, Ohio, y es un portavoz elocuente de la visión católica sobre la justificación.

Otros eruditos que no han abandonado el protestantismo, ahora argumentan que el concepto de imputación de la justicia de Cristo en la justificación no es bíblico. Por ejemplo, Robert Gundry, del Westmont College, escribió: "la doctrina de que la justicia de Cristo es imputada a los pecadores creyentes, necesita ser abandonada". ${ }^{36}$

En 1994, un grupo de evangélicos y católicos romanos, bajo el liderazgo de Charles Colson y Richard John Neuhaus, elaboró un documento titulado "Evangélicos y católicos juntos: La misión cristiana en el tercer milenio". ${ }^{37}$ El documento afirma que "somos justificados a través de la fe a causa de Cristo”, pero no dice nada acerca de la justificación solo por la fe, nada acerca de la justicia imputada de Cristo, y nada acerca de la justificación forense (sola). Aquellos que sostienen la visión tradicional de la justificación están convencidos de que este documento básicamente "trivializó la Reforma". ${ }^{38}$

En 1997, los signatarios de este documento, después de

${ }^{35}$ Scottt y Kimberly Hahn, Rome Sweet Home: Our Journey to Catholicism (San Francisco: Ignatius Press, 1993).

${ }^{36}$ Robert Gundry, "Why I Didn't Endorse 'The Gospel of Jesus Christ: An Evangelical Celebration. . .' Even Though I Wasn't Asked to", Books and Culture 7, no. 1 (2001): 9.

37"Evangelicals and Catholics Together: Christian Mission in the Third Millennium”, First Things 43 (May 1994): 15-22.

${ }^{38}$ Sproul, "Forensic Nature of Justification", 49. 
un año de estudio, emitieron una declaración aclaratoria titulada "El don de la salvación". ${ }^{39}$ Aunque en este documento se declara que "lo que aquí afirmamos está de acuerdo con lo que las tradiciones de la Reforma han entendido por justificación solo por la fe (sola fide)", $4^{40}$ en realidad se siguen aceptando los contornos esenciales de la enseñanza católica romana.

El 31 de octubre de 1999 (aniversario de la publicación de las 95 tesis de Lutero en 1517), en Augsburgo, Alemania (la ciudad que dio su nombre a la primera confesión luterana de fe), altos funcionados de la Federación Luterana Mundial y de la Iglesia Católica Romana emitieron una "Declaración conjunta sobre la doctrina de la justificación”. ${ }^{41}$ En ella se afirma que las diferencias que persisten entre luteranos y católicos no justifican más ninguna división eclesiástica. La declaración pretende haber logrado un consenso en torno a verdades básicas y "una comprensión compartida de la justificación", ${ }^{42}$ negando haber alcanzado un acuerdo pleno sobre toda la doctrina. Muchas iglesias luteranas, tanto dentro como fuera de la Federación, rechazaron la declaración y el presidente del Sínodo de Luteranos de Mis-

39"The Gift of Salvation", Christianity Today, December 8, 1997, 35-7.

40Ibíd., 36.

41"Joint Declaration on the Doctrine of Justification", consultado el 2 de octubre de 2017, http://www.vatican.va/roman_curia/pontifical_councils/chrstuni/documents/rc_pc_chrstuni_doc_31101999_ cath-luth-joint-declaration_en.html. Para una discusión sobre esta declaración, véase, por ejemplo, Henri A. Blocher, "The LutheranCatholic Declaration on Justification", en Justification in Perspective: Historical Developments and Contemporary Challenges, ed. Bruce L. McCormack (Grand Rapids, MI: Baker, 2006), 197-217.

42“Joint Declaration on the Doctrine of Justification”, párrafo 14. 
souri, A. L. Barry, denunció el documento como una "traición al Evangelio de Jesucristo". ${ }^{43}$ Más de ciento cincuenta teólogos firmaron una protesta contra la mencionada declaración. Aun así, una lectura atenta de esta, revela que las diferencias distintivas entre las posiciones protestantes y católicas no han sido abandonadas. ${ }^{44}$

\section{La "nueva perspectiva" de Pablo}

Encabezada por el triunvirato constituido por E. P.

43"Lutheran Church -Missouri Synod press release", October 15, 1999, citado en Raoul Dederen, "The Joint Declaration on the Doctrine of Justification: One Year Later”, Ministry, November 2000, 13.

44Para una demostración de cómo los católicos no han cambiado sus puntos de vista desde Trento, véase especialmente Schreiner, Faith Alone, 209-30; Klaas Runia, "Justification and Roman Catholicism", en Right with God: Justification in the Bible and the World, ed. D. A. Carson (Grand Rapids, MI: Baker, 1998), 197-215. La mayoría de las secciones de la declaración hacen una separación entre las posiciones luterana y católica sobre los puntos respectivos, aun cuando hay un intento de reconciliar esas diferencias. Por ejemplo, en la sección 4.2, titulada "La justificación como perdón del pecado y como hacer justo", el párrafo 23 (que habla de la justificación como perdón del pecado) es el punto de vista luterano, en tanto que el párrafo 24 (que habla de cómo Dios hace justo al creyente) es el punto de vista católico. Nótese lo que ninguno de los dos afirma: que la justificación es solo por la fe, a través de la justicia imputada y forense de Cristo (solamente), y que es posible tener la seguridad de la salvación. Para una recopilación de todos los principales documentos relacionados con el reciente acercamiento entre protestantes y católicos en torno a la doctrina de la justificación que incluye una evaluación amigable, véase, por ejemplo, Anthony N. S. Lane, Justification in Catholic-Protestant Dialogue: An Evangelical Assessment (London: T \& T Clark, 2002). 
Sanders, ${ }^{45}$ James Dunn, ${ }^{46}$ y N. T. Wright ${ }^{47}$ a finales de los años 70 y principio de los años 80, y continuando hasta el presente, se ha desarrollado la llamada "nueva perspectiva" de Pablo que no pretende presentar una posición sobre la justificación que sea fundamentalmente antitética a los intereses de los reformadores, sino que busca más bien ofrecer perspectivas correctivas adicionales a esa posición tradicional.

Hay puntos importantes en los que esta nueva perspectiva da apoyo a la visión protestante histórica,,$^{48}$ y otros énfasis proporcionan un contexto más amplio (pero aún armonioso) para entender la justificación de lo que a menudo se ha considerado en la visión tradicional. ${ }^{49}$

${ }^{45}$ E. P. Sanders, Paul and Palestinian Judaism: A Comparison of Patterns of Religion (Philadelphia: Fortress, 1977).

${ }^{46}$ James D. G. Dunn, "The New Perspective on Paul”, Bulletin of the John Rylands Library 65 (1983): 95-122. Véanse también sus últimos trabajos, especialmente James D. G. Dunn, The New Perspective on Paul, ed. rev. (Grand Rapids, MI: Eerdmans, 2008), James D. G. Dunn, "New Perspective View”, en Justification: Five Views, ed. James K. Beilby y Paul Rhodes Eddy (Downers Grove, IL: IVP Academic, 2011), 176-201.

${ }^{47}$ N. T. Wright, "The Paul of History and the Apostle of Faith", Tyndale Bulletin 29 (1978): 61-88. Para un estudio más exhaustivo del mismo autor, véase N. T. Wright, Justification: God's Plan and Paul's Vision (Downers Grove, IL: IVP, 2009).

${ }^{48}$ Por ejemplo: (1) la justificación es forense (una declaración legal divina) y no transformadora (haciendo a alguien justo); (2) la obediencia perfecta es necesaria para estar en buena relación con Dios; y (3) la ira de Dios es propiciada por la muerte de Cristo.

${ }^{49}$ Estos incluyen, especialmente: (1) el contexto del tribunal divino, (2) el panorama general del pacto y el propósito de Dios para los descendientes de Abraham, y (3) la dimensión escatológica de la justificación (el veredicto final es anunciado de antemano). Schreiner 
En algunas áreas cruciales, sin embargo, la nueva perspectiva parece apartarse de la comprensión protestante tradicional sobre la justificación y los conceptos afines a ella. ${ }^{50}$ En primer lugar, se construye sobre una nueva comprensión del judaísmo del siglo I, que rechaza la visión de la Reforma de que el judaísmo era una religión legalista en la que uno se ganaba la salvación por obras de la ley. Más bien, como Sanders resume, la religión judía se puede describir como un "nomismo pactual": "la salvación es por gracia. . .; las obras son la condición para permanecer 'en', pero con estas no se obtiene la salvación". ${ }^{51}$ La objeción de Pablo no fue dirigida hacia este nomismo pactual, sino hacia el rechazo de Cristo como único medio de salvación por parte del judaísmo.

En segundo lugar, de acuerdo a Dunn y Wright, la referencia de Pablo a las "obras de la ley" no trata del inten-

proporciona evidencia para la conclusión de que estas "perspectivas más amplias" armonizan y enriquecen el punto de vista de la Reforma. Schreiner, Faith Alone, 239-64.

${ }^{50}$ Para esta sección estoy en deuda no solo con los escritos de Sanders, Dunn y Wright, sino también con aquellos que han hecho una crítica constructiva de sus puntos de vista. Véase, en particular, Schreiner, Faith Alone, 239-61; John Piper, The Future of Justification: A Response to N. T. Wright (Wheaton, IL: Crossway, 2007); Guy Prentiss Waters, Justification and the New Perspectives on Paul (Phillipsburg, NJ: P\&R, 2004). Véase también Garwood P. Anderson, Paul's New Perspective: Charting a Soteriological Journey (Downers Grove, IL: InterVarsity, 2016); Mark A. Seifrid, Christ, Our Righteousness: Paul's Theology of Justification, New Testament Studies in Biblical Theology 9 (Downers Grove, IL: InterVarsity, 2000); Stephen Westerholm, Justification Reconsidered: Rethinking a Pauline Theme (Grand Rapids, MI: Eerdmans, 2013). original.

${ }^{51}$ Sanders, Paul and Palestinian Judaism, 543. Cursiva en el 
to de guardar la ley para ser salvos por parte de los judíos (como en el entendimiento tradicional de la Reforma), sino que se refiere más bien a las leyes del judaísmo como la circuncisión, la observancia del sábado y las leyes dietéticas que funcionaban como "insignias étnicas" del judaísmo, marcando así una división entre judíos y gentiles..$^{22}$

En tercer lugar, la "justicia de Dios" es definida como su fidelidad a las promesas pactuales hechas a Abraham, y no como una virtud moral o como la conformidad con una norma que es su propio carácter, como lo entendieron los reformadores. ${ }^{53}$

En cuarto lugar, en contraste con los reformadores que veían la justificación de forma soteriológica (cómo uno es justo ante Dios), Wright entiende la justificación principalmente de forma eclesiológica. Desde su perspectiva,

la justificación no trata de cómo alguien llega a ser un cristiano. Es la declaración de que han llegado a ser cristianos.... Lo que Pablo quiere decir con justificación, en este contexto, debe ser claro. No se trata tanto de "cómo te conviertes en cristiano" sino de "cómo puedes decir quién es miembro de la familia del pacto". ${ }^{54}$

En quinto lugar, los defensores de la nueva perspectiva de Pablo afirman que "el problema fundamental de Israel

${ }^{52}$ Véase, por ejemplo, Dunn, "New Perspective View”, 189-95; Wright, Justification, 116-8. Compare con la crítica realizada por Schreiner, Faith Alone, 249-52.

53Véase Dunn, "New Perspective View”, 182-3; Wright, Justification, 64-71.

${ }^{54}$ N. T. Wright, What Saint Paul Really Said: Was Paul of Tarsus the Real Founder of Christianity? (Grand Rapids, MI: Eerdmans, 1997), 122, 125. Cursiva en el original. 
fue su fracaso a la hora de bendecir al mundo" (un problema instrumental), en contraste con la comprensión de los reformadores sobre Pablo, que enfatiza "la pecaminosidad inherente de Israel” (un problema ontológico). ${ }^{55}$

En sexto lugar, los defensores de la nueva perspectiva de Pablo niegan que el concepto de imputación de la Reforma sea bíblico. Wright categóricamente declara: "Si Pablo usa el lenguaje del tribunal de justicia, no tiene ningún sentido decir que el juez imputa, imparte, confiere, transmite o de alguna otra forma transfiere su justicia ya sea al demandante o al acusado". ${ }^{56}$ Ninguna justicia es imputada por Dios al creyente. ${ }^{57}$

Finalmente, los partidarios de la nueva perspectiva entienden regularmente la frase pístis Christoû no como una referencia a la "fe en Cristo" por parte del creyente, como lo entendían los reformadores, sino más bien como una referencia a la "fe o fidelidad de Cristo". ${ }^{8}$

¿Hasta dónde estas diferencias del punto de vista tradicional, sobre varios aspectos de la justificación, son fieles a las Escrituras? ¿Y hasta qué punto se alejan de la evidencia bíblica?

${ }^{55}$ Resumido por Schreiner, Faith Alone, 244. Véase también Wright, Justification, 195.

${ }^{56}$ Wright, What Saint Paul Really Said, 98. Para una crítica, véase Schreiner, Faith Alone, 253-61.

${ }^{57}$ En lugar de imputación, Wright aboga por el concepto de representación. El Mesías "representa a su pueblo, ahora apropiadamente sustituyéndolos, asumiendo él mismo la muerte que merecían para que ellos mismos no la sufrieran”. Wright, Justification, 105.

${ }^{58}$ Véase, por ejemplo, Dunn, "New Perspective View", 196-8. 


\section{Alternativas adventistas al punto de vista tradicional de la Reforma ${ }^{59}$}

En las últimas décadas ha habido un número de voces adventistas que se oponen al punto de vista de la Reforma sobre la justificación forense, incluyendo al concepto de imputación de la justicia de Cristo. Ven todo el modelo legal de la justificación como no bíblico o como una expresión culturalmente condicionada de la expiación que estaría hablando a la mentalidad primitiva en tiempos bíblicos, pero que ahora es trascendida por una visión más amplia de la expiación que elimina esta imputación forense.

Hay otros adventistas que aceptan la justificación forense en principio, pero consideran que la justificación significa más que la imputación de la justicia de Cristo e incluyen también el proceso por el cual Cristo realmente hace justos a los creyentes. Según este punto de vista, la justificación es primordialmente "hacer justo", y no solo "declarar justo", o de lo contrario solo sería una ficción legal. A pesar de las protestas en contra, los seguidores de este punto de vista parecen adoptar importantes argumentos católicos utilizados contra los reformadores del siglo XVI. La justificación es a la vez la justicia imputada e impartida, a juicio de estos intérpretes adventistas.

Algunos adventistas mantienen que la justificación significa solo el perdón de los pecados pasados cuando uno

${ }^{59}$ Evité intencionalmente identificar por nombres a individuos o grupos dentro de esta sección de este estudio con la esperanza de que el foco se mantenga sobre el tema bajo discusión y no sobre individuos o partidarios de las distintas posiciones dentro del adventismo. En este estudio tampoco se hace referencia al punto de vista de algunos adventistas que creen en una justificación "corporativa", "objetiva” o "universal” que se percibe como ocurriendo en la cruz. Esta posición requiere un extenso tratamiento y evaluación por separado en otro lugar. 
llega por primera vez a Cristo, pero después de esta justificación inicial, la aceptación de Dios se basa en la justicia infusa de Cristo que hace que uno sea justo y, por lo tanto, aceptable a la vista de Dios. Vinculado a esta posición, está el entendimiento de que hay una necesidad de absoluta impecabilidad por parte del pueblo de Dios en el tiempo del fin, la cual hará que la justificación objetiva o imputada ya no sea necesaria porque el pueblo de Dios ha alcanzado un estado de santificación donde dicha justificación imputada es completamente reemplazada por la justicia impartida de Cristo.

\section{A modo de conclusión}

Después de este breve repaso de los diferentes puntos de vista sobre la justificación por la fe, surgen algunas preguntas. ¿̇Es sólida la posición de la Reforma sobre la justificación? ¿Deberíamos volver a Roma, o ir en alguna otra dirección como las sugeridas por otras perspectivas antes mencionadas? La única manera de responder a estas preguntas es poniendo a prueba los diferentes puntos de vista por medio de la Palabra de Dios. ¿Cuál es la enseñanza bíblica sobre la justificación? En la segunda parte de este estudio se discutirá la respuesta a esta pregunta desde la perspectiva del AT.@

Richard M. Davidson davidson@andrews.edu Seventh-day Adventist Theological Seminary Andrews University, EE.UU.

Recibido: 10/11/2017 Aceptado: 20/11/2017 